\title{
Commentary Clinical trial update: National Cancer Institute of Canada
} Kathy Pritchard ${ }^{1}$ and Tim Whelan ${ }^{2}$

\author{
${ }^{1}$ Toronto Sunnybrook Regional Cancer Centre \\ 2Juravinski Regional Cancer Centre \\ Corresponding author: Kathy Pritchard, kathy.pritchard@sw.ca \\ Published: 12 January 2005 \\ Breast Cancer Res 2005, 7:48-51 (DOI 10.1186/bcr979) \\ (C) 2005 BioMed Central Ltd
}

\begin{abstract}
The Breast Cancer Site Group (BCSG) of the National Cancer Institute of Canada (NCIC) Clinical Trials Group (CTG) has conducted a wide variety of clinical trials focussing on large phase III trials of adjuvant chemotherapy, adjuvant hormonal therapy, and optimal delivery of adjuvant radiation therapy. The Group has also fostered, together with the NCIC CTG Investigational New Drug (IND) Program, a series of phase II and phase I/II studies which will be carried through if possible, into the phase III setting.
\end{abstract}

\section{Introduction}

The Breast Cancer Site Group (BCSG) of the National Cancer Institute of Canada (NCIC) Clinical Trials Group (CTG) conducts clinical trials spanning a spectrum of research designs. The Investigational New Drug (IND) programme, chaired and co-chaired by Drs Elizabeth Eisenhauer and Lesley Seymour, interfaces with the BCSG to carry out phase II trials with a variety of new agents. The BCSG strategy is to test new agents that may be suitable for movement forward into larger phase III randomized trials either in metastatic disease or, particularly, in the adjuvant setting. The Group also targets phase I/ll studies of combinations of agents that may be moved forward into phase III trials in the adjuvant, neoadjuvant, or metastatic setting. It is the philosophy of the Group that large trials of adjuvant therapy are most important in terms of translating the maximum clinical benefit to the greatest number of patients with breast cancer.

Currently, five very interesting trials are worthy of particular mention.

\section{MA.22}

The NCIC CTG has conducted considerable investigation into the taxanes and their role in the treatment of breast cancer. Dr Maureen Trudeau in our group chaired one of the first large phase II studies of taxotere in metastatic breast cancer [1]. Published in the Journal of Clinical Oncology, that trial showed a $55 \%\left(40 \%\right.$ for $75 \mathrm{mg} / \mathrm{m}^{2}$ and $63 \%$ for $100 \mathrm{mg} / \mathrm{m}^{2}$ ) overall response rate to taxotere in first-line therapy of metastatic breast cancer, and it was one of the pivotol studies leading to approval of taxotere in the therapy of metastatic breast cancer. Following on from these data, Trudeau then chaired the MA.15 trial. A phase I/II study conducted in patients with metastatic disease, MA.15 explored the optimal doses of the combination of taxotere and epirubicin with and without the use of colonystimulating factor. That trial, which was recently completed $[2,3]$, showed an extremely impressive overall response rate of $70 \%$ for women treated with this combination. Because this combination was so impressive, the Group was interested in developing it further for potential use in adjuvant therapy. With this in mind, we have moved forward to a trial in the locally advanced and inflammatory setting. It is felt that this more closely replicates the adjuvant setting, in which disease may not be as widespread as in metastatic disease, and hence higher dosages may be tolerable.

The MA.22 study has a phase $1 / / I$ design and is being conducted in women with locally advanced and inflammatory breast cancer. To date, four doses of taxotere and epirubicin given at 3-week intervals have been explored. Beginning at taxotere $75 \mathrm{mg} / \mathrm{m}^{2}$ and epirubicin $75 \mathrm{mg} / \mathrm{m}^{2}$ with $6 \mathrm{mg}$ pegfilgrastim, three patients have been treated at each level, moving up to $75 \mathrm{mg} / \mathrm{m}^{2}$ taxotere and $120 \mathrm{mg} / \mathrm{m}^{2}$ epirubicin. At this fourth level, two out of three patients developed dose limiting toxicities. Thus, the maximum tolerated dosage has been reached, and the next lower dose - taxotere $75 \mathrm{mg} / \mathrm{m}^{2}$ and epirubicin $105 \mathrm{mg} / \mathrm{m}^{2}$ - will be used for further testing. The phase II portion of the trial is about to begin and will involve the treatment of a total of 30 patients at dosages of epirubicin and taxotere of $105 \mathrm{mg} / \mathrm{m}^{2}$ and $75 \mathrm{mg} / \mathrm{m}^{2}$, respectively, with pegfilgrastim. A second phase I/II protocol examining taxotere and epirubicin given in a dose-dense manner every 2 weeks will also be part of this trial. End-points will include overall response rate, pathological complete response rate, and disease-free and overall survival. 
MA.22 has provided a unique opportunity for translational research directed at drug resistance to this unique combination of drugs. Core biopsies of material that is fast frozen are taken from each patient in the study before therapy, after three cycles of therapy and after six cycles of therapy. Dr Amadeo Parissenti, who has developed gene signatures relating to taxotere and epirubicin resistance [4], will be testing these specimens to determine patterns of development of resistance during combination therapy with these two drugs. We believe that this model, in which multiple core biopsies are taken and frozen, will prove extremely valuable for future studies, in addition to providing data regarding resistance to taxotere and epirubicin in this setting.

\section{MA.27}

The NCIC CTG, together with the North American Intergroup (Cancer and Leukemia Group B, Eastern Cooperative Oncology Group, Southwest Oncology Group, and North Central Cancer Treatment Group), European Organization for Research and Treatment of Cancer and Breast International Group, recently conducted the MA.17 trial, in which postmenopausal women who had completed 4.5-6 years of tamoxifen in the adjuvant setting were randomly assigned to receive either 5 years of letrozole $2.5 \mathrm{mg} /$ day or placebo for 5 years. In that trial, recent reports $[5,6]$ have shown that the use of letrozole resulted in significantly fewer breast cancer events (local recurrence, distant recurrence, contralateral breast cancer, death), and that this effect was significant in both node-negative and node-positive subgroups (Figs 1-3). In addition, in the node-positive subset overall survival has been significantly improved by the use of letrozole (ASCO 2004). Over a similar time period, reports have indicated a better recurrence-free survival with anastrozole than with tamoxifen when given to postmenopausal women as adjuvant hormonal therapy $[7,8]$, and a recurrence-free survival advantage when either anastrozole [9] or exemestane [10] was substituted for tamoxifen after 2-3 years of adjuvant tamoxifen therapy. These trials have established the aromatase inhibitors as one of the standard options in the adjuvant treatment of postmenopausal women with receptor-positive tumours.

Based on this body of work, the NCIC CTG has recently initiated a trial that will be conducted in collaboration with the North American Intergroup (Cancer and Leukemia Group B, Eastern Cooperative Oncology Group, Southwest Oncology Group, and North Central Cancer Treatment Group), and with European Organization for Research and Treatment of Cancer, International Breast Cancer Study Group and Breast International Group. This trial, MA.27, will randomly assign postmenopausal women with oestrogen receptor and/or progesterone receptor positive tumours in the adjuvant setting to receive exemestane $25 \mathrm{mg} /$ daily or anastrozole $1 \mathrm{mg} /$ daily for

\section{Figure 1}

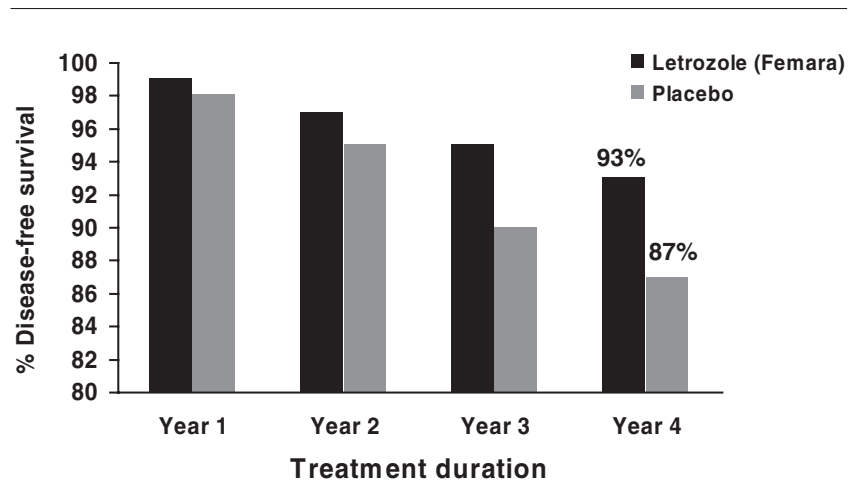

MA.17 results: disease-free survival by treatment duration. There is increasing benefit in terms of estimated disease-free survival with treatment duration. Adapted with permission from Goss and coworkers [6].

Figure 2

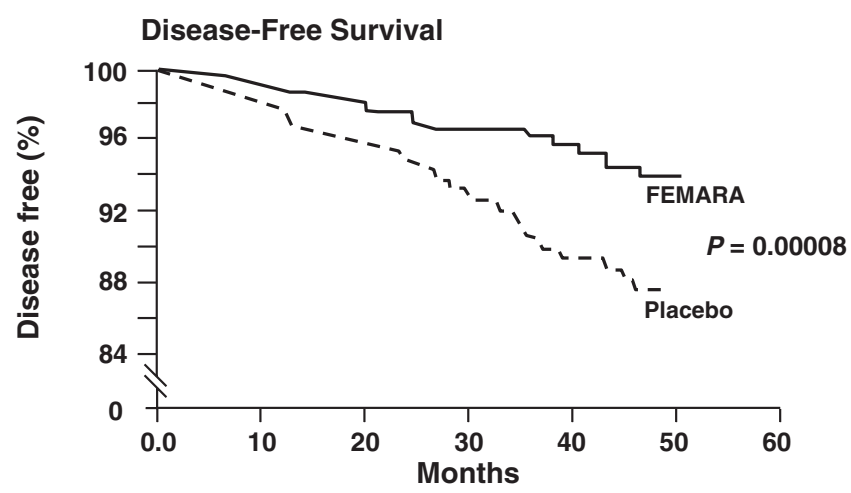

MA.17 results: disease-free survival over time. Adapted with permission from Goss and coworkers [6].

Figure 3

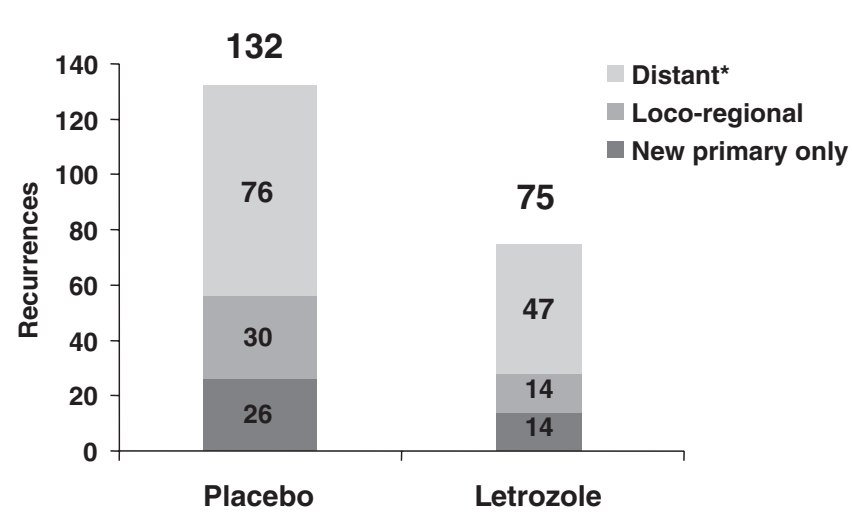

MA.17 results: total recurrences of breast cancer. *Patients may have more than one recurrence site. Adapted with permission from Goss and coworkers [6]. 
5 years. Women will also be randomly assigned to receive celecoxib $400 \mathrm{mg}$ twice daily or placebo for 3 years. Although celecoxib is currently being given for a 3-year period, this may be extended to 5 years depending on upcoming safety data, which is under review.

The concept of the trial is to determine which of the nonsteroidal aromatase inhibitor anastrozole and the steroidal aromatase inhibitor exemestane is superior in terms of preventing recurrence and/or death from breast cancer, and whether either has a superior toxicity profile. There are now considerable data suggesting that all of the aromatase inhibitors are associated with some increased risk for development of osteoporosis and/or bone fracture. However, it is believed that the steroidal aromatase inhibitor may have less of an effect in this regard. In addition, there are some data suggesting that exemestane may be more likely to interact favourably with the nonsteroidal anti-inflammatory celecoxib. Celecoxib has been shown in preclinical models to have some anticancer activity, and may interact differentially with steroidal and nonsteroidal aromatase inhibitors. MA.27 is designed to test all of these questions with regard to antitumour efficacy and short, intermediate and long-term side effects. The study will be accompanied by a variety of correlative substudies, including studies of quality of life, bone and lipid substudies, and basic science correlative studies examining molecular profiles and other biomarkers in relation to study results.

\section{Investigational New Drug trials}

In addition, the group is about to initiate two very interesting IND trials. These trials, IND163 and IND164, will study agents that have been selected for their unique mechanisms of action and the possibility of favourable antitumour activity.

The first of these trials, IND164, is a randomized phase II trial examing the role of the anticlusterin, antisense molecule OGX-011, together with taxotere, as first-line chemotherapy for metastatic breast cancer. OGX-011 is given as a 2-hour intravenous infusion weekly and docetaxel $75 \mathrm{mg} / \mathrm{m}^{2}$ is given every 3 weeks as a 1 -hour intravenous infusion. The OGX-011 antisense, developed in the laboratory of Dr Martin Gleeve in British Columbia, has been shown to have activity in preclinical (Gleeve M, personal communication) and clinical (Eisenhauer E, personal communication) settings. It has been suggested that OGX-011 may be particularly active in conjunction with the taxanes. Thus, this trial may provide interesting phase II data that could lead to further studies.

The second trial, IND163, is a randomized phase II trial of two schedules of the oral rapamycin analogue RAD-001 in first-line therapy for metastatic breast cancer. RAD-001
TOR), a key signal transduction mediator. RAD-001 will be given orally in a 4-week schedule either daily for 28 days or weekly (days $1,8,15$ and 21 ).

\section{MA.20}

A fifth important study that is ongoing in the NCIC CTG involves the comparison of regional nodal plus breast versus breast-only radiation therapy in women who have undergone breast conserving surgery. Randomized trials have demonstrated that locoregional radiation therapy following mastectomy for patients at high risk for locoregional recurrence after intravenous cyclophosphamide methotrexate and flourouracil or hormonal therapy for short duration improves survival $[11,12]$. Currently, the majority of women with early breast cancer are treated with breast conserving surgery and breast irradiation. Modern breast cancer treatments also involve more frequent use of anthracycline-based chemotherapy and long-duration hormonal therapy. It is possible that, by adding regional irradiation, survival may be improved compared with breast irradiation alone after breast conserving surgery and systemic therapy. However, regional irradiation may be associated with an increased risk for pneumonitis, lymphoedema and, for patients with left-sided cancer, cardiovascular disease. The goal of the study is to determine whether adding regional irradiation to modern systemic therapy improves survival with acceptable limited toxicity in patients treated with breast conservation therapy. This study will also of course examine local and distant recurrence rates, cosmetic results and quality of life. As of August 2004, over 1000 patients had been recruited to this trial of a proposed sample size of 1800 .

\section{Conclusion}

In summary, the NCIC CTG Breast Cancer Site Group is committed to trials that will examine and develop new agents with innovative mechanisms of action, which may prove useful in the metastatic or adjuvant setting (IND163, IND164); that will study interesting drugs or combinations in the phase I/II setting, which may be moved forward for therapy of adjuvant, neoadjuvant, or metastatic disease (MA.22); that will explore optimal systemic regimens in the adjuvant setting (MA.27); that will explore the role of local and locoregional therapy in terms of their effect both on locoregional recurrence and on distant recurrence and overall survival (MA.20); and that will explore the optimal multidisciplinary use of radiation, surgery and systemic therapy in the treatment of breast cancer (MA.20).

\section{Competing interests}

$\mathrm{KP}$ has been a consultant with Aventis, AstraZeneca, Roche, Pharmacia Inc., Ortho-Biotech, Pfizer, YM Biosciences and Biomira. KP has received research funding either directly through per case funding for studies, or indirectly through the National Cancer Institute 
of Canada Clinical Trials Group, contracted with pharmaceutical companies from Pharmacia Inc., AstraZeneca, Bristol Myers Squibb, Aventis, Amgen, Ortho-Biotech and Pfizer.

\section{References}

1. Trudeau ME, Eisenhauer EA, Higgins B, Letendre F, Lofters WS, Norris B, Vandenberg T, Delorme F, Muldal A: Docetaxel in patients with metastic breast cancer: a phase II study of the National Cancer Institute of Canada-Clinical Trials Group. $J$ Clin Oncol 1996, 14:422-428.

2. Trudeau ME, Crump M, Latreille J, Pritchard KI, Palmer M, Tu D, Shepherd L, Shear N, Shapiro L, Oldfield S, et al.: Escalating doses of docetaxel and epirubicin as first line therapy for metastatic breast cancer: a phase I/II study of the National Cancer Institute of Canada Clinical Trials Group [abstract]. Pro Am Soc Clin Oncol 1999, 18:117a.

3. Trudeau ME, Crump M, Latreille J, Pritchard KI, Palmer M, Tu D, Shepherd L, Shear N, Shapiro L, Oldfield S, et al:: Escalating doses of docetaxel and epirubicin as first line therapy for metastatic breast cancer: A phase I/II study of the National Cancer Institute of Canada - Clinical Trials Group [abstract 443]. Proc Am Soc Clin Oncol 1999, 18:117a.

4. Parissenti AM, Gannon BR, Villeneuve DJ, Kirwan-rhude AF, Chadderton A, Gluck S: Lack of modulation of MDR1 gene expression by dominant inhibition of cAMP-dependent protein kinase in doxorubicin-resistant MCF-7 breast cancer cells. Int $J$ Cancer 1999, 82:893-900.

5. Goss PE, Ingle JN, Martino S, Robert NJ, Muss HB, Piccart MJ, Castiglione M, Tu D, Shepherd L, Pater JL: Updated analysis of the NCIC CTG Ma.17 randomized placebo $(P)$ controlled trial of letrozole (L) after five years of tamoxifen in postmenopausal women with early stage breast cancer [abstract. Proc Am Soc Clin Oncol 2004, 22:88s.

6. Goss PE, Ingle JN, Martino S, Robert NJ, Muss HB, Piccart MJ, Castiglione M, Tu D, Shepherd L, Pritchard KI, et al.: A randomized trial of letrozole in postmenopausal women after five years of tamoxifen therapy for early-stage breast cancer. $N$ Eng J Med 2003, 349:1793-1802.

7. The ATAC Trialists Group: Anastrozole alone or in combination with tamoxifen versus tamoxifen alone for adjuvant treatment of postmenopausal women with early breast cancer: first results of the ATAC randomised trial. Lancet 2002, 359:21312139.

8. The ATAC Trialists Group: Anastrozole alone or in combination with tamoxifen versus tamoxifen alone for adjuvant treatment of postmenopausal women with early-stage breast cancer: results of the ATAC (Arimidex, Tamoxifen Alone or in Combination) trial efficacy and safety update analyses. Cancer 2003, 98:1802-1810.

9. Boccardo F, Rubagotti A, Amoroso D, Mesiti M, Massobrio M, Benedetto C, Porpiglia M, Rinaldini M, Paladini G, Distante V, et al.: Anastrozole appears to be superior to tamoxifen in women already receiving adjuvant tamoxifen treatment. Breast Cancer Res Treat 2004, 85:192.

10. Coombes RC, Hall E, Gibson L, Paridaens R, Jassem J, Delozier $\mathrm{T}$, Jones SE, Alvarez I, Bertelli G, Ortmann O, et al:: A randomized trial of exemestane after two to three years of tamoxifen therapy in postmenopausal women with primary breast cancer. N Eng J Med 2004, 350:1081-1091.

11. Ragaz J, Stewart DJ, Le N, Plenderleith IH, Spinelli JJ, Basco VE, Wilson KS, Knowling MA, Coppin CM, Paradis M, et al.: Adjuvant radiotherapy and chemotherapy in node-positive premenopausal women with breast cancer. N Engl J Med 1997, 337:956-962.

12. Overgaard M, Hansen PS, Overgaard J, Rose C, Andersson M, Bach F, Kjaer M, Gadeberg CC, Mouridsen HT, Jensen MB, et al.: Postoperative radiotherapy in high-risk premenopausal women with breast cancer who receive adjuvant chemotherapy. N Engl J Med 1997, 337:949-955. 